\title{
Determination of Microalbuminuraia and Its Relation to HTN in Type 2 Diabetic Patients and General People
}

\author{
Nowshin Monir*, Zebunnesa Zeba, Sharmin Sultana, Ijajul Islam \\ Department of Public Health and Informatics, Jahangirnagar University, Dhaka, Bangladesh \\ Email address: \\ nowshinmonir@yahoo.com (N. Monir), zebunnesa.zeba@juniv.edu (Z.Zeba), sharminsultanajuphi51@gmail.com (S. Sultana), \\ ijajulju2270@gmail.com (I. Islam) \\ ${ }^{*}$ Corresponding author
}

\section{To cite this article:}

Nowshin Monir, Zebunnesa Zeba, Sharmin Sultana, Ijajul Islam. Determination of Microalbuminuraia and Its Relation to HTN in Type 2 Diabetic Patients and General People. European Journal of Preventive Medicine. Vol. 7, No. 6, 2019, pp. 117-122.

doi: 10.11648/j.ejpm.20190706.15

Received: October 23, 2019; Accepted: November 12, 2019; Published: November 26, 2019

\begin{abstract}
Background: Microalbuminuria is a clinical marker of glomerular injury and identified as a risk of progressive renal damage, cardiovascular disease and morbidity. Hypertension (HTN) is a worldwide public health problem andcommonly coexists with Diabetes Mellitus (DM). Objective: The aim of the study was todetermine the prevalence of microalbuminuriain type 2diabetic patients and general people and the relationship between microalbuminuria withHTN and other clinical parametersin these twogroups of people. Methodology: A cross-sectional study was carried out using a pretested structured questionnaire amongrandomly selected 107 participants aged from 35-70 years. Out of 107 participants 64 persons were type 2 diabetic patients and 43 were healthy individuals. Biochemical analysis of blood and urine samples was performed. Result: The prevalence of microalbuminuria was $17.2 \%$ in diabetic patients and $25.6 \%$ ingeneral people whereas the prevalence of HTN was $48.4 \%$ among diabetic patients and $51.6 \%$ in normal healthy persons. Regardless of the group considered, when microalbuminuria was analyzed according to the different clinical parameters, microalbuminuricpatients had significantly highersystolic $(\mathrm{p}=0.03)$ diastolic $(\mathrm{p}=0.02)$ blood pressure, urine creatinine $(\mathrm{p}=0.000)$, serum creatinine $(\mathrm{p}=0.012)$, urine albumin ( $\mathrm{p}=0.019$ ) and GFR ( $\mathrm{p}=0.000$ ). Microalbuminuria was found to be associated with HTN (odds ratio [OR] 3.5, 95\% confidence interval $[\mathrm{CI}]$ 1.2-9.7). Conclusion: The study concluded thatmicroalbuminuria prevalence is high among general people and HTN has a significant relationship with microalbuminuria. These findings suggest early screening of microalbuminuria and the proper management of other clinical parameters to halt and prevent end stage renal disease and cardiovascular risk in future.
\end{abstract}

Keywords: Microalbuminuria, Hypertension, Type 2 Diabetes Mellitus, General People

\section{Introduction}

Microalbuminuria is a condition defined as urinary albumin/creatinine ratio (UACR) higher than the threshold value $\left(20-200 \mu \mathrm{g} \min ^{-1}\right.$ or $\geq 30$ to $<300 \mathrm{mg}$ per day) obtained from studies assessing nephropathy development risk in diabetes patients [1-2]. Initially, this condition was found to be a predictor of future progression of renal disease in patients with diabetic nephropathy [3, 4]. However, according to recent studies, microalbuminuria has found to be associated with higher cardiovascular risk and end-stage renal disease in patients with other conditions [5-7] as well as in the general population $[8,9]$. Microalbuminuria prevalence varies according to ethnicity and significantly more common in Asians than white European [10, 11]. Microalbuminuria prevalence increases with increased diabetes duration, age, diastolic blood pressure, glycated haemoglobin, fasting plasma glucose [12].

One of the most important risk factor for cardiovascular disease is HTN [13]. HTN association with elevated urinary albumin excretion level is well-established [14-16]. Microalbuminuria incidence is more common among hypertensive patients, even in non-diabetic patients [17]. Essential HTN produces clinical proteinuria and significantly reduce renal function in $5-15 \%$ of patients. Several 
epidemiological studies have also shown the presence of proteinuria or microalbuminuria as an independent predictor of cardiovascular morbidity and mortality in patients with essential HTN [18-19].

$\mathrm{DM}$ is the most common endocrine disorder globally [20] and is associated with multiple pathologies, including nephropathy. At present type 2 DM represents almost $90 \%$ of all cases of diabetes [21,22]. Around $8.3 \%$ of the world's adult population has DM [23] where both women and men have equal rates [21]. Annually, around 5\%-10\% of type 2 DM patients with microalbuminuria develop diabetic nephropathy [24]. DM and HTN are common diseases that coexist and patients with type $2 \mathrm{DM}$ are at least twice likely to have HTN than non-diabetic population [25].

The study aimed to determine the prevalence of microalbuminuria and its association with HTN and other clinical parameters in a group of type 2 DM patients and a group of general population.

\section{Method}

A total of 107 patients were included in the study where 64 persons were type 2 diabetic patients and 43 were healthy individuals. The study area was Jahangirnagar University campus. The study was conducted over a period of six months from November 2017 to April 2018 and the age range was 35-70 years. Informed consent was obtained from each participant. A pretested structured questionnaire regarding the demographic data such as age, gender, height, body weight, family history of DM, blood pressure and smoking habit were recorded for each patient through faceto-face interview. Pregnant and patients with disease condition that will cause positive microalbuminuria measurement such as fever, menstruation, end-stage renal disease, haematuria, leukocyturia, or heart failure were excluded from the study.

\section{Anthropometric and laboratory measurements}

Four trained personnel carried out the physical examinations using standard procedures. Weights and heights were measured up to the nearest $0.1 \mathrm{~kg}$ and $0.1 \mathrm{~cm}$, respectively with the subjects wearing only light clothing and not wearing shoes. The waist circumference (WC) was determined at the narrowest point between the lower rib margin and the iliac crest while the subject exhaled. The body mass index (BMI) was calculated as the weight $(\mathrm{kg})$ divided by the square of the height $(\mathrm{m})$.

The blood pressure was measured two times at 5-minute intervals using a standard mercury sphygmomanometer (Alpk2 Aneroid sphygmomanometer, Tokyo, Japan). Readings were taken after the patients had been resting comfortably, back supported in the sitting or supine position for at least 5 minutes. The second blood pressure measurement was used as the blood pressure for the individual. HTN was defined as systolic blood pressure (SBP $\geq 140 \mathrm{mmhg}$ ) and/ or diastolic blood pressure (DBP $\geq 90 \mathrm{mmhg}$ ) or use of antihypertensive medications [26].

After fasting for at least $8 \mathrm{~h}$, blood samples and random mid-stream urine samples were obtained for biochemical analysis. Using aseptic technique, $10 \mathrm{ml}$ venous blood was drawn by well-trained medical technologist from each subject and was collected in EDTA bottle. Serum was separated by centrifugation ( 15 minutes) at a rate of $3000 \mathrm{rpm}$ at room temperature immediately after the blood was allowed to clot for 30 minutes using Table top Centrifuge (Taiwan). The samples were analyzed immediately using Automatic Analyzer (Clindiag System, USA). The urine creatinine was determined using Jaffe method and urine albumin was measured through immunoturbidimetric procedure. AlbuminCreatinine ratio (ACR) was adapted to categorize subjects as having normo-albuminuria (ACR $<30 \mathrm{mg} / \mathrm{g}$ ), microalbuminuria (ACR $\geq 30$ to $<300 \mathrm{mg} / \mathrm{g}$ ), and macroalbuminuria (ACR $\geq 300 \mathrm{mg} / \mathrm{g}$ ). Statistical analysis was done using SPSS version 20. All of the statistical tests were 2 -tailed, and a $\mathrm{P}$ value $<0.05$ was considered statistically significant.

Table 1. Baseline characteristics of two groups $(n=107)$.

\begin{tabular}{llll}
\hline & $\begin{array}{l}\text { Type 2 Diabetic } \\
\text { Patient }\end{array}$ & $\begin{array}{l}\text { General } \\
\text { People }\end{array}$ & P-Value \\
\hline $\begin{array}{l}\text { Age (Mean } \pm \text { SD) } \\
\text { Gender }\end{array}$ & $50.36 \pm 8.20$ & $50.07 \pm 9.625$ & -- \\
Male & $25(39.1)$ & $24(55.8)$ & 0.09 \\
Female & $39(60.9)$ & $19(44.2)$ & \\
Educational Level & & & \\
No education & $16(25)$ & $4(9.3)$ & \\
Primary education & $10(15.6)$ & $6(14)$ & 0.007 \\
Secondary education & $26(40.6)$ & $12(27.9)$ & \\
Higher education & $12(18.8)$ & $21(48.8)$ & \\
Occupation & & & \\
Government & $6(9.4)$ & $7(16.3)$ & \\
Private & $2(3.1)$ & $1(2.3)$ & \\
Autonomous & $13(20.3)$ & $13(30.2)$ & 0.08 \\
Business & $5(7.8)$ & $2(4.7)$ & \\
House wife & $35(54.7)$ & $13(30.2)$ & \\
Others & $3(4.7)$ & $7(16.3)$ & \\
Income & & & \\
$>10000$ & $16(25)$ & $9(20.9)$ & \\
$10000-30000$ & $32(50)$ & $14(32.6)$ & 0.05 \\
$31000-50000$ & $11(17.2)$ & $9(20.9)$ & \\
$>51000$ & $5(7.8)$ & $27.0512 \pm 4.5$ & \\
BMI (Mean \pm SD) & $26.382 \pm 3.3$ & & \\
\hline
\end{tabular}

The data are presented as means \pm standard errors and percentages $(\%)$. *The $\mathrm{P}$ values were obtained using the chi-square test.

\section{Results}

A total of 107 participants where 64 persons were type 2 diabetic patients (25 males and 39 females) and 43 were general people (24 males and 19 females) were included in the study. Table 1 shows that, when the group of type 2 diabetic patients were compared to general people, majority of the participants of type 2 diabetic patients group were from 46-55 age group (42.2\%), female (60.9\%), had secondary education (40.6\%), and half of them had an income range of TK 10000-30000. 


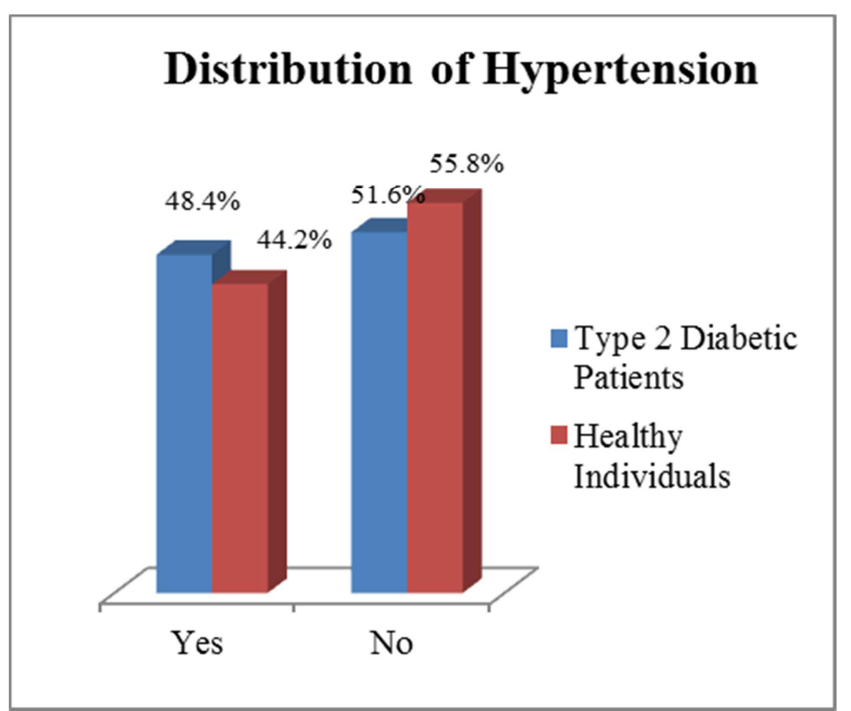

Figure 1. Distribution of Hypertension among participants.

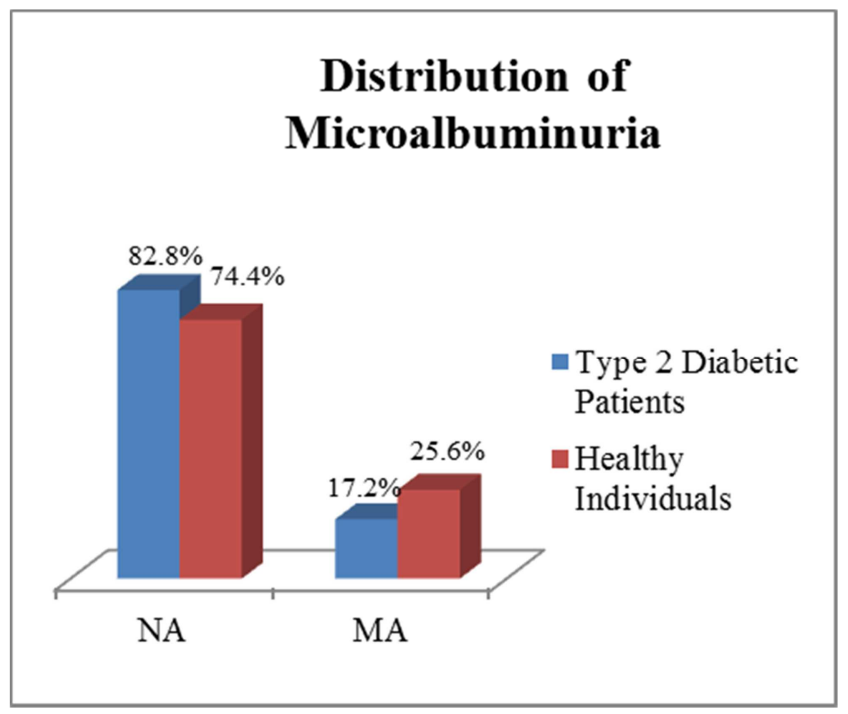

Figure 2. Microalbuminuria status among participants.

In general people, majority of the participants were from $36-55$ age group (37\%), male (55.8\%), had higher education (48.8\%), incomed TK 10000-30000 (32.6\%) and had higher BMI than type 2 diabetic patients group. Significant difference has been observed between patient and control regarding education $(\mathrm{P}=0.007)$. Figure 1 illustrates that $48.4 \%$ diabetic patient and $44.2 \%$ general people had HTN while Figure 2 exhibits that $17.2 \%$ type 2 diabetic patientsand $25.6 \%$ general peoplewere detected with microalbuminuria.

According to table 2 when the blood pressure was compared, in both groups microalbuminuric had statistically significant higher systolic and diastolic pressure. General people also showed higher systolic and diastolic pressure than type 2 diabetic patients group.

Table 3 compares the odds ratio between normoalbuminuric and microalbuminuric participants when the occurrence of microalbuminuria was analyzed, regardless of the group considered. Microalbuminuria was found to be significantly associated with HTN (OR: 3.5, CI: 1.2-9.7). Table 4 shows microalbuminuric had higher urine creatinine $(\mathrm{p}=0.000)$, serum creatinine $(\mathrm{p}=0.01)$, urine albumin $(\mathrm{p}=0.02)$ and GFR $(\mathrm{p}=0.000)$.

Table 2. Comparison of blood pressure between two groups.

\begin{tabular}{llll}
\hline & Type 2 Diabetic Patient & General People & P-Value \\
\hline SBP & & & \\
NA & $119.34 \pm 13.01$ & $122.34 \pm 17.32$ & 0.03 \\
MA & $126.81 \pm 21.60$ & $131.36 \pm 12.667$ & \\
DBP & & & \\
NA & $75.00 \pm 7.97$ & $77.34 \pm 10.39$ & 0.02 \\
MA & $75.00 \pm 7.97$ & $82.37 \pm 9.24$ & \\
\hline
\end{tabular}

The data are presented as means \pm standard errors and percentages $(\%)$.

$\mathrm{SBP}=$ systolic blood pressure, $\mathrm{DBP}=$ diastolic blood pressure.

$\mathrm{NA}=$ Normoalbuminuria, $\mathrm{MA}=$ Microalbuminuria .

*The $\mathrm{P}$ values were obtained using logistic regression.

Table 3. Relationship of Microalbuminuria with anthropometric measurements, DM and HTN.

\begin{tabular}{llll}
\hline & OR & $\mathbf{9 5 \%}$ CI & P-Value \\
\hline BMI $\left(\mathrm{kg} / \mathrm{m}^{2}\right)$ & 0.97 & $0.85-1.10$ & 0.63 \\
WC (male) & 1.03 & $1.0-1.05$ & 0.05 \\
WC (female) & 0.98 & $0.95-1.0$ & 0.07 \\
DM & 1.6 & $0.64-4.2$ & 0.295 \\
Family history of DM & 1.4 & $0.58-3.8$ & 0.482 \\
HTN & 3.5 & $1.2-9.7$ & 0.018 \\
Family history of HTN & 2.16 & $0.77-6.0$ & 0.114 \\
\hline
\end{tabular}

$\mathrm{OR}=$ Odds Ratio, $\mathrm{CI}=$ Confidence Interval.

$\mathrm{BMI}=$ body mass index, $\mathrm{WC}=$ waist circumference, $\mathrm{DM}=$ diabetes mellitus, HTN=hypertension.

Table 4. Relationship between the occurrence of microalbuminuria and other clinical parameters.

\begin{tabular}{llll}
\hline & NA & MA & P-Value \\
\hline FBG $(\mathrm{mmol} / \mathrm{L})$ & $13.27 \pm 3.20$ & $7.28 \pm 3.45$ & 0.10 \\
$\mathrm{UCr}(\mathrm{gl} / \mathrm{L})$ & $.836 \pm 0.27$ & $1.14 \pm 0.2$ & 0.00 \\
$\mathrm{SCr}(\mu \mathrm{mol} / \mathrm{L})$ & $0.886 \pm 0.233$ & $1.22 \pm 0.72$ & 0.01 \\
Ualb $(\mathrm{mg} / \mathrm{L})$ & $13.27 \pm 3.2$ & $155.09 \pm 174.49$ & 0.02 \\
GFR $(\mathrm{mL} / \mathrm{min}$ per & $93.64 \pm 15.87$ & $69.77 \pm 18.91$ & 0.00 \\
$\left.1.73 \mathrm{~m}^{2}\right)$ & $188.74 \pm 38.64$ & $188.77 \pm 46.42$ & 0.99 \\
$\mathrm{TC}(\mathrm{mg} / \mathrm{dL})$ & $191.54 \pm 57.53$ & $193.72 \pm 59.76$ & 0.87 \\
$\mathrm{TG}(\mathrm{mg} / \mathrm{dL})$ & $37.49 \pm 7.51$ & $34.79 \pm 7.19$ & 0.13 \\
$\mathrm{HDL}(\mathrm{mg} / \mathrm{dL})$ & $115.17 \pm 37.84$ & $113.09 \pm 43.33$ & 0.82 \\
LDL $(\mathrm{mg} / \mathrm{dL})$ & & & \\
\hline
\end{tabular}

The data are presented as means \pm standard error.

$\mathrm{NA}=$ Normoalbuminuria, $\mathrm{MA}=$ Microalbuminuria, $\mathrm{FBG}=$ fasting blood glucose, Ucr=urine creatinine, $\mathrm{SCr}=$ serum creatinine, Ualb=urine albumin, $\mathrm{GFR}=$ glomerular filtration rate, $\mathrm{ACR}=$ albumin tocreatinine ratio, $\mathrm{TC}=$ total cholesterol, $\mathrm{TG}=$ triglycerides, $\mathrm{HDL}=$ high density lipids, $\mathrm{LDL}=$ low density lipids.

*The $\mathrm{P}$ values were obtained using logistic regression.

\section{Discussion}

The presence of microalbuminuria and heart disease is strongly linked to Kidney disease. Although microalbuminura serves as a marker to detect increased risk, but does not directly cause cardiovascular events [27].

In our study, two groups showed significant difference regarding educational level $(\mathrm{p}=0.007)$. Another study in 
Bangladesh has also found the positive association between education and DM. However, association of DM with educational level varies internationally. Positive association was found in China and India. In contrast, another Chinese study found that, DM prevalence was generally unaffected by educational level and high-income group had higher prevalence. Moreover, both developing and developed countries studies have found that, there is an inverse association between diabetes and educational level [28]. The study found that, the prevalence of HTN was $48.4 \%$ in type 2 diabetic patient group and $44.2 \%$ in general people group. A review article to identify the prevalence of HTN in type 2 diabetic patients, found that HTN rates were typically high among type 2 diabetic patients in all regions where most studies presented rates above $50 \%$, while many presented rates above $75 \%$ [29]. According to $\mathrm{WHO}$, in 2008, the overall prevalence of HTN was globally around $40 \%$ in adults aged 25 and over [30].

In our study, the prevalence of microalbuminuria was $17.2 \%$ in type 2 diabetic patient group which is a bit lower compared to other studies in India and Pakistan where the prevalence was $29 \%$ [31] and $34 \%$ [32] respectively. However, Studies in the white UK population revealed microalbuminuria prevalence was $7 \%-9 \%[33,34]$, which was 31\% in Mexican Americans [33], 26\% in Pima Indians and $35 \%$ in Nauruans and Hispanic Americans [35-37]. The prevalence found in our study could be lower because the diabetic patients were found more conscious about their health status. In the study, microalbuminuria prevalence in general people was $25.6 \%$. According to the Third National Health and Nutrition Examination Survey, the prevalence of microalbuminuria in the general US population was $6.1 \%$ for men and 9.7\% for women [38], 6\% in Australians, [39] $6.6 \%$ in Netherland, [40] 20\% in native Canadians [41] and $36.9 \%$ in Singaporeans $\geq 40$ years [42].

A positive link has been established between HTN and microalbuminuria [43]. The most significant contributing factor in the pathogenesis and the progression of abnormal ACR is elevated blood pressure, which eventually leads to the development of diabetic nephropathy in both Type 1 and Type 2 diabetic patients $[44,45]$. In the present study microalbuminuric had significantly higher SBP $(p=0.03)$ and DBP $(p=0.02)$ than normoalbuminuric subjects which is consistent with findings from other studies [32, 46, 47]. Microalbuminuric patients tend to have higher DM, family history of DM, family history of HTN, but no independent significant association was observed in the present study although in most of the studies a good association has been observed [48].

In addition, our study has found positive association between urine creatinine $(\mathrm{p}=0.000)$, serum creatinine $(p=0.012)$, urine albumin $(p=0.019)$ and GFR $(p=0.000)$ with microalbuminuria which is similar to other study [49]. No significant association was found between two groups regarding TC, TG, HDL and LDL. A study conducted in china also found similar result [50].

\section{Conclusion}

The study revealed that the prevalence of microalbuminuria was higher in general people than type 2 diabetic patients and had positive association with HTN. Microalbuminuria was also related to higher urine creatinine, serum creatinine, urine albumin and GFR. The study suggests early screening todetect microalbuminuria for intervention and prevention of end stage renal disease and cardiovascular disease.

\section{Consent}

After describing all steps of the study, a written consent was obtained from all participants and their confidentiality was assured. All of the written consent has been collected and preserved by the authors.

\section{Ethical Approval}

The study does not contain any clinical intervention and was a screening in that population where only blood was collected.

\section{Competing Interests}

Authors have declared that no competing interests exist.

\section{References}

[1] National Kidney Foundation. K/DOQI clinical practice guidelines for chronic kidney disease: evaluation, classification, and stratification. Am J Kidney Dis 2002; 39: $1-266$.

[2] Mancia G, De Backer G, Dominiczak A, Cifkova R, Fagard R, Germano G. 2007 Guidelines for the Management of Arterial Hypertension: The Task Force for the Management of Arterial Hypertension of the European Society of Hypertension (ESH) and of the European Society of Cardiology (ESC). J Hypertens 2007; 25: 1105-87.

[3] Parving HH, Oxenboll B, Svendsen PA, Christiansen JS, Andersen AR. Early detection of patients at risk of developing diabetic nephropathy. A longitudinal study of urinary albumin excretion. ActaEndocrinol (Copenh) 1982; 100: 550-5.

[4] Viberti GC, Hill RD, Jarrett RJ, Argyropoulos A, Mahmud U, Keen $H$. Microalbuminuria as a predictor of clinical nephropathy in insulin-dependent diabetes mellitus. The Lancet 1982; 1: 1430-2.

[5] Haneda M, Kikkawa R, Togawa M, Koya D, Kajiwara N, Uzu T. High blood pressure is a risk factor for the development of microalbuminuria in Japanese subjects with non-insulindependent diabetes mellitus. J Diabetes Complications 1992; 6: $181-5$.

[6] Wachtell K, Ibsen H, Olsen MH, Borch-Johnsen K, Lindholm LH, Mogensen CE. Albuminuria and cardiovascular risk in hypertensivepatients with left ventricular hypertrophy: the LIFE study. Ann Intern Med 2003; 139: 901-6. 
[7] Forman JP, Brenner BM. 'Hypertension' and 'microalbuminuria': the bell tolls for thee. Kidney Int 2006; 69: 22-8.

[8] Choi HS, Sung KC, Lee KB. The prevalence and risk factors of microalbuminuria in normoglycemic, normotensive adults. ClinNephrol 2006; 65: 256-61.

[9] Konta T, Hao Z, Abiko H, Ishikawa M, Takahashi T, Ikeda A. Prevalence and risk factor analysis of microalbuminuria in Japanese general population: the Takahata study. Kidney Int 2006; 70: 751-6.

[10] Dixon A, Raymond N, Mughal S, Rahim A, O'Hare JP, Kumar S, Barnett A. Prevalence of microalbuminuria and hypertension in South Asians and white Europeans with type 2 diabetes: a report from the United Kingdom Asian Diabetes Study (UKADS). Diab and Vasc Dis Res 2006; 3: 22-5.

[11] Summerson J, Bell R, Konen J. Racial differences in the prevalence of microalbuminuria in hypertension. Am J Kidney Dis 1995; 26: 577-9.

[12] Varghese A, Deepa R, Rema M, Mohan V. (2001). Prevalence of microalbuminuria in type 2 diabetes mellitus at a diabetes centre in southern India. Postgrad Med J 2001; 77: 399-402.

[13] Lawes CM, Rodgers A, Bennett DA, Parag V, Suh I, Ueshima $\mathrm{H}$. Blood pressure and cardiovascular disease in the Asia Pacific region. J Hypertens 2003; 21: 707-16.

[14] Romundstad S, Holmen J, Hallan H, Kvenild K, Ellekjaer H. Microalbuminuria and all-cause mortality in treated hypertensive individuals: does sex matter? The NordTrondelag Health Study (HUNT), Norway. Circulation 2003; 108: 2783-9.

[15] Giaconi S, Levanti C, Fommei E, Innocenti F, Seghieri G, Palla L. Microalbuminuria and casual and ambulatory blood pressure monitoring in normotensives and in patients with borderline and mild essential hypertension. Am J Hypertens 1989; 2: 259-61.

[16] Gerber LM, Shmukler C, Alderman MH. Differences in urinary albumin excretion rate between normotensive and hypertensive, white and nonwhite subjects. Arch Intern Med 1992; 152: 373-7.

[17] Parving HH, Mogensen CE, Jensen HA, Evrin PE. Increased urinary albumin-excretion rate in benign essential hypertension. The Lancet 1974; 1: 1190-2.

[18] Bianchi S, Bigazzi R, Baldari G, Campese VM. Microalbuminuria in patients with essential hypertension: Effects of several antihypertensive drugs. Am J Med 1992; 93: 525-8.

[19] Verdecchia P, Reboldi GP. Hypertension and microalbuminuria: The new detrimental duo. Blood Press 2004; 13: 198-211.

[20] Bakari AG, Narayan D. Diabetes mellitus Complicating BThalassemia: A case. Annals of African medicine 2003; 2: 368.

[21] Vos T, Flaxman AD, Naghavi M, Lozano R, Michaud C, Ezzati M. Years lived with disability (YLDs) for 1160 sequelae of 289 diseases and injuries 1990-2010: a systematic analysis for the Global Burden of Disease Study 2010. The Lancet. 2012; 380: 2163-96.
[22] Melmed s, Polonsky k, Larsen PR, Henry K. Williams textbook of endocrinology. 12 ed. Elsevier/Saunders; 2011.

[23] Shi Y, Hu FB. The global implications of diabetes and cancer. The Lancet. 2014; 383: 1947-8.

[24] Parving HH, Lehnert H, Bröchner-Mortensen J, Gomis R, Andersen S, Arner P. Irbesartan in Patients with Type 2 Diabetes and Microalbuminuria Study Group. The effect ofirbesartan on the development of diabetic nephropathy in patients with type 2 diabetes. New Engl J Med 2001; 345: 870-8.

[25] Dodson PM. Hypertension and diabetes. Curr Med Res Opin 2002; 18: 48-57.

[26] Whelton PK, Carey RM, Aronow WS, Casey DE, Collins KJ, Himmelfarb CD, De Palma SM. 2017 Guideline for the Prevention, Detection, Evaluation, and Management of High Blood Pressure in Adults. J Am Coll Cardiol 2017; 4.

[27] Wrone EM, Carnethon MR, Panaliappan LP, et al. Association of dietary protein intake and microalbuminuria in healthy adults: Third National Health and Nutrition Examination Survey. Am J Kid Dis 2003; 41: 580-7.

[28] Akter S, Rahman MM, Abe SK, Sultana P. Prevalence of diabetes and prediabetes and their risk factors among Bangladeshi adults: a nationwide survey. Bulletin of the World Health Organization 2014; 92: 204-13.

[29] Ann DC, Roberto P, and Shahnaz K. Prevalence of hypertension and obesity in patients with type 2 diabetes mellitus in observational studies: a systematic literature review. Diabetes Metab Syndr Obes 2013; 6: 327-38.

[30] World Health Organization. Global Health Observatory (GHO) data. Raised blood pressure.

[31] Vijeth SB, Girish I. Nandini HV. A cross sectional study to assess the prevalence of microalbuminuria in patients with type 2 diabetes mellitus. Int J Res Med Sci 2018; 6: 117-20.

[32] Ahmedani MY, Hydrie MZI, Iqbal A, Gul A, Mirza WB, Basit. A Prevalence of Microalbuminuria in Type 2 Diabetic Patients in Karachi: Pakistan A Multi-center Study. J Pak Med Assoc 2005; 55: 382-6.

[33] Marshall SM, Alberti KGMM. Comparison of the prevalence and associated features of abnormal albumin excretion in insulindependent and non-insulin-dependent diabetes. Q J Med. 1989; 70: 61-71.

[34] Amos AF, McCarty DJ, Zimmet P. The rising global burden of diabetes and its complications. Diabet Med 1997; 14: 1-85.

[35] Haffner SM, Morales PA, Gruber MK, et al. Cardiovascular risk factors in non-insulin dependent diabetic subjects with microalbuminuria. Arterioscler Thromb. 1993; 13: 205-10.

[36] Nelson RG, Kunzelman CL, Pettit DJ, et al. Albuminuria in type 2 (non-insulindependent) diabetes mellitus and impaired glucose tolerance in Pima Indians. Diabetologia. 1989; 32: $870-6$.

[37] Hamman RF, Franklin GA, Mayer EJ, et al. Microvascular complication of NIDDM in Hispanics and non-Hispanic whites. Diabetes Care. 1991; 14: 655-63.

[38] Jones CA, Francis ME, Eberhardt M, et al. Microalbuminuria in the US population: Third National Health and Nutrition Examination Survey. Am J Kidney Dis 2002; 39: 445-59. 
[39] Atkins RC, Polkinghorne KR, Briganti EM, et al. Prevalence of albuminuria in Australia. Aus Diab Kidney Int 2004; 66 (S92): S22-4.

[40] Hillege HL, Fidler V, Diercks GF, et al. Urinary albumin excretion predicts cardiovascular and noncardiovascular mortality in general population. Circulation 2002; 106: $1777-$ 82.

[41] Zacharias JM, Young TK, Riediger ND, et al. Prevalence, risk factors and awareness of albuminuria on a Canadian First Nation: a community-based screening study. BMC Public Health 2012; 12: 290.

[42] Sabanayagam C, Shankar A, Saw SM, et al. Socioeconomic status and microalbuminuria in an Asian population. Nephrol Dial Transplant 2009; 24: 123-9.

[43] Koroshi A. Microalbuminuria, is it so important? HIPPOKRATIA 2007, 11, 3: 105-7.

[44] Susztak k, Sharma K, Schiffer M, McCue P, Ciccone E, Böttinger PE. Genomic strategies for diabetic nephropathy. J Am Society of Nephrol 2003; 14: 271-8.

[45] Mogensen CE, Poulsen PL. Epidemiology of microalbuminuria in diabetes and in the background population. CurrOpin in Nephrol and Hypertens 1994; 3: 24856.

[46] Ali A, Taj A, Amin MJ, Iqbal F, Iqbal Z. Correlation between microalbuminuria and hypertension in Type 2 diabetic patients. Pak J Med Sci 2014; 30: 511-4.

[47] Shin KE, Roh YK, Cho KH, Han KD, Park YG, Kim DH, $\mathrm{Kim} \mathrm{YH}$. The prevalence of hypertension in relation with the normal albuminuria range in type 2 diabetes mellitus within the South Korean population: The Korean National Health and Nutrition Examination Survey, 2011-2012. Prim Care Diab 2017; $11: 281-7$.

[48] Yan L, Ma J, Guo X, Tang J, Zhang J, Lu Z, Wang H, Cai X, Wang L. Urinary albumin excretion and prevalence of microalbuminuria in a general Chinese population: a crosssectional study. MC Nephrology 2014, 15: 165.

[49] Altibi HI. Microalbuminuria among Type 2 Diabetic Patients in the Gaza Strip. Thesis paper 2007.

[50] Lee ES, Tang WE. The prevalence of albuminuria among diabetic patients in a primary care setting in Singapore. Singapore Med J 2015; 56: 681-6. 